\title{
Next-generation in vitro blood-brain barrier models: benchmarking and improving model accuracy
}

Raleigh M. Linville $e^{1,2}$ and Peter C. Searson ${ }^{1,2,3^{*}}$ (D)

\begin{abstract}
With the limitations associated with post-mortem tissue and animal models, In vitro BBB models enable precise control of independent variables and microenvironmental cues, and hence play an important role in studying the BBB. Advances in stem cell technology and tissue engineering provide the tools to create next-generation in vitro BBB models with spatial organization of different cell types in 3D microenvironments that more closely match the human brain. These models will be capable of assessing the physiological and pathological responses to different perturbations relevant to health and disease. Here, we review the factors that determine the accuracy of in vitro BBB models, and describe how these factors will guide the development of next-generation models. Improving the accuracy of cell sources and microenvironmental cues will enable in vitro BBB models with improved accuracy and specificity to study processes and phenomena associated with zonation, brain region, age, sex, ethnicity, and disease state.
\end{abstract}

Keyword: Blood-brain barrier, Brain microvascular endothelial cells, Induced pluripotent stem cells, Microenvironment, Microenvironmental cues, Model accuracy, Differentiation, Gene expression

\section{Background}

Establishing how the blood-brain barrier (BBB) responds to different chemical, physical, and biological perturbations is key to understanding the link between bloodbrain barrier $(\mathrm{BBB})$ health and brain health. In vitro $\mathrm{BBB}$ models enable independent control over the spatial organization of cellular components and microenvironmental cues, and hence are complementary to animal models, which display species-dependent differences, and studies in humans where imaging has limited resolution and tissue samples are difficult to obtain [1]. Highly reductive in vitro models formed by confluent monolayers of brain microvascular endothelial cells (BMECs) on transwells enable high-throughput screening of specific

*Correspondence: searson@jhu.edu

${ }^{1}$ Institute for Nanobiotechnology, Johns Hopkins University, Baltimore, MD, USA

Full list of author information is available at the end of the article functional properties, however, more complex models are needed to study a broader range of biological processes and to recapitulate the physiological and pathological responses of human brain endothelium. Recently, advances in stem cell technology and tissue engineering have provided the tools to create these models. Here, we consider the important factors in establishing the accuracy of $\mathrm{BBB}$ models, with a focus on tissue-engineered models incorporating stem-cell derived BMEC-like cells (iBMECs). The emerging understanding of the human BBB from single-cell/nucleus sequencing studies provides the foundations to benchmark in vitro models with human, zonation, brain region, ethnicity, sex, age, and disease state specificity. Key factors in developing these next-generation models include: (1) improved characterization of the human BBB for accurate benchmarking of in vitro models, (2) improved cell engineering techniques to mimic gene and protein expression of BMECs and supporting cell types, and (3) improved tissue engineering original author(s) and the source, provide a link to the Creative Commons licence, and indicate if changes were made. The images or other third party material in this article are included in the article's Creative Commons licence, unless indicated otherwise in a credit line to the material. If material is not included in the article's Creative Commons licence and your intended use is not permitted by statutory regulation or exceeds the permitted use, you will need to obtain permission directly from the copyright holder. To view a copy of this licence, visit http://creativecommons.org/licenses/by/4.0/. The Creative Commons Public Domain Dedication waiver (http://creativeco mmons.org/publicdomain/zero/1.0/) applies to the data made available in this article, unless otherwise stated in a credit line to the data. 
methods to mimic microenvironmental cues present within the cerebrovasculature.

\section{Accuracy of in vitro BBB models Defining accuracy}

The observable characteristics of an in vitro BBB model are derived from two factors: the cellular components (e.g., protein and gene expression profiles) and the local microenvironment established in the model. These two factors are interrelated since the microenvironment can have significant influence on the protein and gene expression profiles of the source cells. The observable characteristics of the model encompass the functional responses to physiological, therapeutic, or pathological perturbations (e.g., barrier function, response to cytokines, stress response, etc.) Therefore, the accuracy of a BBB model can be defined as the level to which the observable characteristics recapitulate the human $\mathrm{BBB}$. In principle, the accuracy can be quantified with values expected to be between 0 and 1 . However, establishing the accuracy of in vitro $\mathrm{BBB}$ models has been challenging as the observable characteristics of the human BBB are limited and/ or inconsistent. For example, the permeability of small molecular weight compounds is inconsistently reported in animal models [2, 3], and has not been directly measured in humans. To overcome this limitation, comparison of the gene expression profiles of endothelial cells in vitro and in the human brain (transcriptomic accuracy) has emerged as a useful proxy for model accuracy $[4,5]$. With the advent of single cell and single nucleus RNA sequencing methods, gene expression of cell types in the BBB can be assessed from human brain tissue. However, the relationship between gene expression and protein expression depends on many factors including post-transcriptional regulation, protein secretion, and RNA/protein degradation [6], and hence transcriptomic accuracy should be assessed in the context of protein expression and functional responses.

\section{How accurate do BBB models need to be?}

The transwell model, incorporating a monolayer of Madin Derby Canine Kidney epithelial cells (MDCKs, established in 1958), has been a workhorse in BBB research for many years. This model is widely used for measurement of solute permeability, assessment of transendothelial cell migration, as well as for many other biologically- and clinically-relevant processes. Although MDCKs are epithelial cells, they express tight junctions and hence paracellular transport across confluent monolayers is negligible. As a consequence, solute transport is dominated by active transport or passive diffusion across the apical and basolateral cell membranes [7]. Assuming that differences in lipid composition do not influence kinetics, passive transport across MDCK monolayers is considered to mimic passive transport across endothelial monolayers in the brain. MDCK cells have also been genetically engineered to assess whether small molecule solutes are substrates for P-gp efflux pump. Primary and immortalized brain microvascular endothelial cells (BMECs) have also been widely used in BBB models but often show batch-to-batch variability, loss of barrier function during ex vivo culture, and very low transendothelial electrical resistance (TEER), a measure of paracellular barrier integrity $[8,9]$. Despite these limitations, these cell sources have enabled important foundational studies of the BBB, especially related to solute transport and cell transmigration.

From an engineering perspective, in vitro models only need to recapitulate the particular function of interest. For example, transwell models, while highly reductive, enable rapid assessment of solute permeability across endothelial and epithelial barriers. Similarly, microfluidic organ-on-a-chip devices (e.g., lung-on-a-chip, liver-on-a-chip, etc.) do not attempt to recapitulate all aspects of organ function but are invaluable for highthroughput screening of specific processes or functions, or in answering specific research questions. Due to the complexity of the human $\mathrm{BBB}$, in vitro models should be engineered to answer specific research questions, acknowledging that over-engineering is wasted effort and that under-engineering may compromise the relevance of findings. Establishing the accuracy of BBB models is a major challenge and will require protocols for assessing the response to different perturbations or stresses, e.g., physical forces (e.g., mechanical forces, electromagnetic radiation, temperature, hypoxia), endogenous factors (e.g., associated with lifestyle or disease), exogenous factors (e.g., therapeutics), chemical factors (e.g., ROS, inflammatory factors), or toxins and pathogens.

\section{The challenges in establishing model accuracy}

As described above, the accuracy of an in vitro BBB model is dependent on the cellular components and the local microenvironment, which together define the observable characteristics. Along the arterio-venous (AV) axis, from arterioles to capillaries to venules, there are significant differences in perivascular and mural cell organization, blood flow patterns, and association with neurons and glial cells [10]. In pre-capillary arterioles, the endothelium is surrounded by smooth muscle cells (SMCs) among other supporting cell types, and experiences a relatively high shear stress. In capillaries, BMECs wrap around to form tight junctions with themselves and their upstream and downstream neighbors, and are surrounded by pericytes and astrocyte end-feet. In venules, BMECs are directly surrounded by mural cells distinct 
from their arteriolar neighbors and a perivascular space located between the basement membrane and astrocytic glia limitans. Some biological functions occur preferentially at different locations along the AV axis, including trafficking of immune cells, cancer cells, pathogens, plasma, and nanoparticles [11-13]. Many other aspects of the microenvironment, including physical dimensions, flow rates, pressure, shear stress, and neurovascular coupling [14] vary along the AV axis and provide important inputs for the engineering design of BBB models.

Recent single cell transcriptomic studies have established that gene expression of BMECs in the brain varies along the AV axis both in mice $[13,15,16]$ and humans $[4,5]$. Species-dependent differences between BMECs in the mouse and human brain have been reported to include $\sim 10 \%$ of all genes [4], but the implications of these differences remain to be fully explored. Along the $\mathrm{AV}$ axis, BMECs and mural cells display zonated gene and protein expression which underlie distinct biological functions, as described above $[4,5,13,15,16]$. However, these studies are based on relatively small human sample sizes and different isolation protocols, which makes direct comparison challenging. In addition, limited access to non-pathological human brain tissue, also contributes to the difficulty in benchmarking BMECs in models to BMECs in the human brain. Ultimately, there is a need to establish datasets from multiple individuals using standardized protocols. In addition to zonation specificity, the observed characteristics of the human BBB are dependent on many factors, including brain region, age, sex, ethnicity, and disease state. In particular, differences associated with sex and ethnicity are not yet well understood, and hence benchmarking is currently not possible. However, in vitro models incorporating iPSCs across these variables could contribute to our understanding and guide future animal and human studies.

In summary, next-generation in vitro models of the BBB should consider zonation, brain region, age, sex, ethnicity, and disease state specificity. While variations associated with these factors demonstrate that it is not possible to design a universal BBB model, for some applications generic or reductive models will be more appropriate. For example, a generic model may recapitulate BMEC barrier integrity at the level of capillaries and be sufficient for studies of drug delivery. Similarly, a reductive model may incorporate multiple cell types but in a non-physiological geometry (e.g., 2D). Next, we review two major contributors to model accuracy: cell source and microenvironment.

\section{Accuracy of the cell source}

To overcome limitations associated with MDCKs and primary/immortalized cell lines, and to provide a reproducible and scalable source of cells for BBB research, various differentiation strategies have been developed to generate BMEC-like cells (iBMECs) from induced pluripotent or embryonic stem cells [17]. Many studies have established that confluent monolayers of iBMECs display expression of important EC- and BBB-specific markers at the protein and gene level [17]. To date, the observable characteristics of BBB models using iBMECs have been based on a limited set of functional assays, primarily related to barrier integrity, that recapitulate observations in animal models and/or humans, including high TEER, low solute permeability, and efflux activity [11]. The validation of aspects of BBB function has enabled new paradigm for BBB research where pathological mechanisms are first studied in tissue-engineered iBMEC-based models, taking advantage of the ability to have independent control over experimental variables, and then subsequently verified in animal models or human tissue [18-20].

However, recent comparisons to primary BMECs and other endothelial cell types, show that iBMECs differentiated using current protocols possess reduced endothelial identity (e.g., lower gene and protein expression of VEcadherin compared to other endothelial sources) [17] and elements of epithelial identity (e.g., gene and protein expression of E-cadherin) [21]. Furthermore, the gene expression profiles for iBMECs have not yet been benchmarked to human single-cell BMEC datasets, a key step is establishing model accuracy. Thus, driving iBMEC gene expression towards that of human BMECs and understanding the heterogeneity of differentiated cells will be key towards improving the accuracy of in vitro BBB models.

There are several strategies for driving the identity of iBMECs further towards human BMECs, including (Fig. 1): (1) transcription factor (TF) reprogramming, (2) chemical induction, and (3) the development of novel differentiation approaches that better mimic BBB development [21-26]. Each of these approaches has had success in enhancing BMEC identity, although high levels of similarity to human BMECs has not yet been achieved. TF reprogramming has been used to overexpress brainspecific transcription factors (e.g., SOX18 and TAL1) in non-brain specific iECs which transiently increases TEER and gene expression of BBB markers [22]. iBMECs can be reprogrammed with ETS TFs (e.g., ETV2, ERG, FLI1) to improve endothelial identity, however this process is associated with a loss of barrier function and leads to gene expression profiles more closely resembling non-brain specific iECs $[21,27]$. TGF- $\beta$ inhibition can enhance endothelial and BBB-specificity of iECs and 


epithelial $\longrightarrow$ efflux pump transfection
cell lines

iBMECs $[24,25]$, and activation of $\mathrm{Wnt} / \beta$-catenin signaling (using agonist of $\mathrm{Wnt} / \beta$-catenin signaling, Wnt ligands, or conditioned media from neural progenitor cells) in endothelial progenitor cells upregulates BBBspecific gene expression [26]. While these approaches hold promise and have shown improvements in accuracy of specific BBB or endothelial genes and/or functional properties, they have so far been unable to achieve the physiological barrier properties typical of iBMEC monolayers, and show TEER values comparable to primary and immortalized BMEC sources.

Benchmarking iBMECs to human BMECs will be increasingly challenging due to the emerging understanding of the functional differences associated with zonation, brain region, age, and other factors, as well as the variation between individuals within each group. Therefore, the transcriptomic accuracy of iBMECs will depend on the particular research question to be addressed. For example, recent sequencing data enables benchmarking iBMECs to achieve zonation-specific identity $[4,5]$. The relationship between transcriptomic accuracy of source cells and model accuracy will also be important in creating next-generation models. While increasing transcriptomic accuracy will, in most cases, lead to increased accuracy of the BBB model, it will also depend on the specific genes that are congruent with the target BMECs and hence the biological processes that are recapitulated. Finally, this complexity also makes it difficult to establish the transcriptomic identity of "generic" iBMECs that can be used to study processes where differences associated with zonation, for example, are not important.

\section{Accuracy of the microenvironment}

The local microenvironment plays an important role in defining BBB model accuracy. When primary BMECs are cultured ex vivo they lose BBB-specific transcripts, while endothelial transcripts are less significantly altered [9]. These changes demonstrate the critical importance of microenvironmental cues in maintenance of BBB identity. However, recapitulating the cerebrovascular microenvironment poses many challenges, as outlined below. The brain is characterized by a very high density of neurons and glial cells with an extracellular space $(\sim 20$ volume \%) filled with interstitial fluid containing long-chain macromolecules, primarily proteoglycans. However, the brain does not have a bulk structural extracellular matrix $(E C M)$ as in other tissues. Therefore, to provide structural support for cell culture, in vitro BBB models have largely employed an extracellular matrix material (e.g., collagen, fibrin, etc.) that matches the stiffness of brain tissue. Approaches based on spheroids, which eliminates the need for a structural matrix, are better able to recapitulate the cellular organization in the brain, but vascularization and perfusion of the spheroid core remain a significant challenge.

In addition to the zonation specificity of cell types and their spatial arrangement, other important microenvironmental cues that regulate BMEC phenotype include basement membrane [28], shear stress [29,30], interactions with other cell types (e.g., mural cells) [31,32], cylindrical geometry [33], blood composition [34, 35], and neuronal activity [36]. Tissue-engineered in vitro models of the $\mathrm{BBB}$ provide an opportunity to explore the role of microenvironment on BBB model accuracy in detail, with the key advantage of independent control of experimental variables to assess individual and synergistic effects 


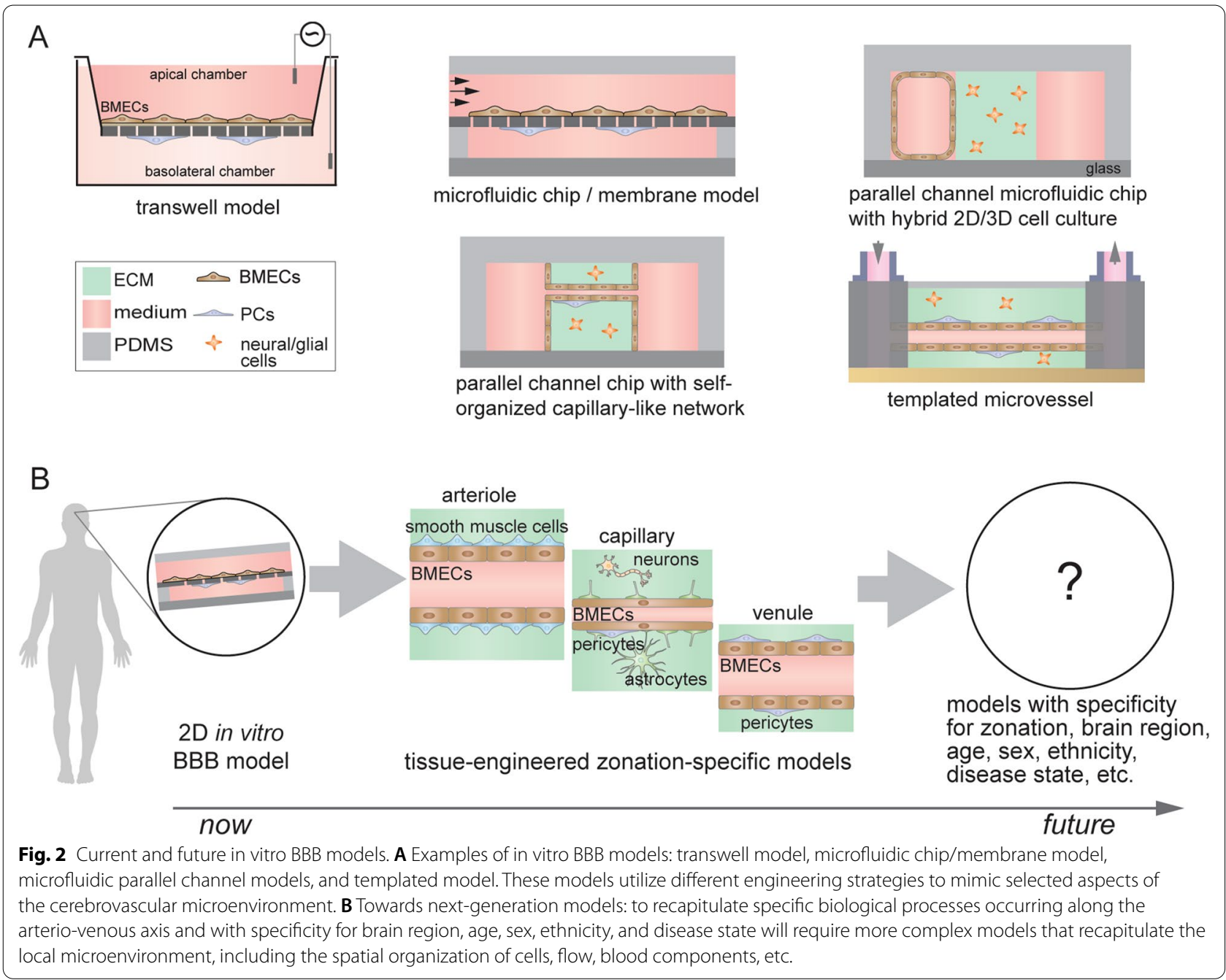

on observable characteristics. Current in vitro model designs capture different aspects of these microenvironmental cues (Fig. 2A) [37], and can be broadly categorized as: (1) 2D microfluidic chip membrane-based models that incorporate shear flow and other cell types [30, 38], (2) parallel channel microfluidic models will hybrid 2D/3D cell culture [39, 40], (3) parallel channel microfluidic models with self-organized microvascular networks [20,31], and (4) templating based devices which generate cylindrical microvessels in an extracellular matrix [41, 42]. Self-organization and templating approaches enable incorporation of a wide repertoire of microenvironmental cues including cylindrical geometry, cell-ECM interactions, and direct cell-cell interactions. These cues can enhance BBB model accuracy compared to shear stress alone, including enriched endothelial identity, unique cytokine and angiogenic responses, and lower paracellular permeability [27]. Across model types, co-cultured pericytes and astrocytes enhance expression of $\mathrm{BBB}$ markers and increase barrier tightness when source BMECs have poor barrier function (e.g., low TEER) [31, 42], while these same effects are attenuated when high TEER is achieved at baseline [11,32].

Despite advances in tissue engineering, BBB models do not fully recapitulate the microenvironment of the $\mathrm{BBB}$ in the human brain. Some important challenges include (Fig. 2B): (1) improved fidelity of the spatial arrangement of BBB cell types in a zonation-specific manner, (2) incorporation of blood components known to be important in communication between the vascular system and the brain, (3) developing strategies for multiscale/hierarchical models along cerebrovascular zones, and (4) recapitulating aspects of neurovascular coupling. While advances in tissue engineering support the feasibility of addressing these challenges, success will require a significant effort within the $\mathrm{BBB}$ research community. 


\section{Conclusions}

Creating next-generation in vitro BBB models will require integration of knowledge from vascular atlases of protein and gene expression in the human brain and the emerging understanding of the role of a broad range of extrinsic factors (microenvironmental cues, supporting cell types, blood components, etc.) on observable characteristics. Stem cell technology provides a pathway for engineering iBMECs and isogenic supporting cells with high transcriptomic similarity to cells in the human brain, but will require advances in cell engineering. Advances in biomaterials and tissue engineering have improved the toolkit for incorporating microenvironmental cues into BBB models, however, significant advances are needed to further improve model accuracy. Despite these challenges, next-generation BBB models will enable studies of diseases of the brain, responses to a wide range of physical, chemical, and biological perturbations, and delivery of therapeutics to the brain. Next-generation models will improve accuracy of the gene expression of cell sources and microenvironments to engineer models that achieve high human-specificity, zonation-specificity, brain region-specificity, and disease state-specificity.

\section{Acknowledgements}

RML acknowledges a National Science Foundation Graduate Research Fellowship under Grant No. DGE1746891.

\section{Authors' contributions}

RML and PCS wrote the manuscript. Both authors read and approved the final manuscript.

\section{Funding}

This work was supported by NIH (NINDS R01NS106008 and NHLBI

R61HL154252) and DTRA (HDTRA1-15-1-0046).

\section{Availability of data and materials}

Not applicable.

\section{Declarations}

Ethics approval and consent to participate

Not applicable.

\section{Consent for publication}

Not applicable.

\section{Competing interests}

The authors declare that they have no competing interests.

\section{Author details}

${ }^{1}$ Institute for Nanobiotechnology, Johns Hopkins University, Baltimore, MD, USA. ${ }^{2}$ Department of Biomedical Engineering, Johns Hopkins University, Baltimore, MD, USA. ${ }^{3}$ Department of Materials Science and Engineering, Johns Hopkins University, Baltimore, MD, USA.

Received: 16 September 2021 Accepted: 24 November 2021 Published online: 07 December 2021

\section{References}

1. Ochocinska MJ, Zlokovic BV, Searson PC, Crowder AT, Kraig RP, Ljubimova JY, Mainprize TG, Banks WA, Warren RQ, Kindzelski A, Timmer W, Liu CH. $\mathrm{NIH}$ workshop report on the trans-agency blood-brain interface workshop 2016 exploring key challenges and opportunities associated with the blood, brain and their interface. Fluids Barriers CNS. 2017. https://doi. org/10.1186/s12987-017-0061-6.

2. Easton AS, Sarker MH, Fraser PA. Two components of blood-brain barrier disruption in the rat. J Physiol. 1997;503(Pt 3):613-23.

3. Shi L, Zeng M, Sun Y, Fu BM. Quantification of blood-brain barrier solute permeability and brain transport by multiphoton microscopy. J Biomech Eng. 2014;136(3):031005.

4. Garcia FJ, Sun N, Lee H, Godlewski B, Galani K, Mantero J, Bennett DA, Sahin M, Kellis M, Heiman M. Single-cell dissection of the human cerebrovasculature in health and disease. bioRxiv. 2021. https://doi.org/10.1101/ 2021.04.26.440975.

5. Yang AC, Vest RT, Kern F, Lee DP, Maat CA, Losada PM, Chen MB, Agam M, Schaum N, Khoury N, Calcuttawala K, Palovics R, Shin A, Wang EY, Luo J, Gate D, Siegenthaler JA, McNerney MW, Keller A, Wyss-Coray T. A human brain vascular atlas reveals diverse cell mediators of Alzheimer's disease risk. bioRxiv. 2021. https://doi.org/10.1101/2021.04.26.441262.

6. Jiang L, Wang M, Lin S, Jian R, Li X, Chan J, Dong G, Fang H, Robinson AE, Consortium GT, Snyder MP. A quantitative proteome map of the human body. Cell. 2020;183(1):269-283 e19.

7. Wong AD, Ye M, Levy AF, Rothstein JD, Bergles DE, Searson PC. The bloodbrain barrier: an engineering perspective. Front Neuroeng. 2013;6:7.

8. Helms HC, Abbott NJ, Burek M, Cecchelli R, Couraud PO, Deli MA, Forster C, Galla HJ, Romero IA, Shusta EV, Stebbins MJ, Vandenhaute E, Weksler B, Brodin B. In vitro models of the blood-brain barrier: an overview of commonly used brain endothelial cell culture models and guidelines for their use. J Cerebr Blood Flow Metab. 2016;36(5):862-90.

9. Sabbagh MF, Nathans J. A genome-wide view of the de-differentiation of central nervous system endothelial cells in culture. eLife. 2020. https:// doi.org/10.7554/eLife.51276.

10. Schaeffer S, ladecola C. Revisiting the neurovascular unit. Nat Neurosci. 2021;24(9):1198-209.

11. DeStefano JG, Jamieson JJ, Linville RM, Searson PC. Benchmarking in vitro tissue-engineered blood-brain barrier models. Fluids Barriers CNS. 2018. https://doi.org/10.1186/s12987-018-0117-2.

12. Kucharz K, Kristensen K, Johnsen KB, Lund MA, Lonstrup M, Moos T, Andresen TL, Lauritzen MJ. Post-capillary venules are the key locus for transcytosis-mediated brain delivery of therapeutic nanoparticles. Nat Commun. 2021;12(1):4121.

13. Yang ANC, Stevens MY, Chen MCB, Lee DVP, Stahli D, Gate D, Contrepois K, Chen WN, Iram T, Zhang LC, Vest RT, Chaney A, Lehallier B, Olsson N, du Bois H, Hsieh R, Cropper HC, Berdnik D, Li LL, Wang EY, Traber GM, Bertozzi CR, Luo J, Snyder MP, Elias JE, Quake SR, James ML, Wyss-Coray T. Physiological blood-brain transport is impaired with age by a shift in transcytosis. Nature. 2020;583(7816):425.

14. Chow BW, Nunez V, Kaplan L, Granger AJ, Bistrong K, Zucker HL, Kumar P, Sabatini BL, Gu C. Caveolae in CNS arterioles mediate neurovascular coupling. Nature. 2020;579(7797):106-10.

15. Vanlandewijck M, He L, Mae MA, Andrae J, Ando K, Del Gaudio F, Nahar K, Lebouvier T, Lavina B, Gouveia L, Sun Y, Raschperger E, Rasanen M, Zarb Y, Mochizuki N, Keller A, Lendahl U, Betsholtz C. A molecular atlas of cell types and zonation in the brain vasculature. Nature. 2018:554(7693):475-80.

16. Zhao L, Li Z, Vong JSL, Chen X, Lai HM, Yan LYC, Huang J, Sy SKH, Tian X, Huang Y, Chan HYE, So HC, Ng WL, Tang Y, Lin WJ, Mok VCT, Ko H. Pharmacologically reversible zonation-dependent endothelial cell transcriptomic changes with neurodegenerative disease associations in the aged brain. Nat Commun. 2020;11(1):4413.

17. Lippmann ES, Azarin SM, Palecek SP, Shusta EV. Commentary on human pluripotent stem cell-based blood-brain barrier models. Fluids Barriers CNS. 2020;17(1):64.

18. Linville RM, DeStefano JG, Sklar MB, Chu CY, Walczak P, Searson PC. Modeling hyperosmotic blood-brain barrier opening within human tissue-engineered in vitro brain microvessels. J Cerebr Blood F Met. 2020;40(7):1517-32.

19. Linville RM, Komin A, Lan X, DeStefano JG, Chu C, Liu G, Walczak P, Hristova K, Searson PC. Reversible blood-brain barrier opening utilizing 
the membrane active peptide melittin in vitro and in vivo. Biomaterials. 2021;275:120942.

20. Blanchard JW, Bula M, Davila-Velderrain J, Akay LA, Zhu L, Frank A, Victor MB, Bonner JM, Mathys H, Lin YT, Ko T, Bennett DA, Cam HP, Kellis $M$, Tsai LH. Reconstruction of the human blood-brain barrier in vitro reveals a pathogenic mechanism of APOE4 in pericytes. Nat Med. 2020;26(6):952-63.

21. LuTM, Houghton S, Magdeldin T, Duran JGB, Minotti AP, Snead A, Sproul A, Nguyen DHT, Xiang J, Fine HA, Rosenwaks Z, Studer L, Rafii S, Agalliu D, Redmond D, Lis R. Pluripotent stem cell-derived epithelium misidentified as brain microvascular endothelium requires ETS factors to acquire vascular fate. Proc Natl Acad Sci USA. 2021. https://doi.org/10.1073/pnas. 2016950118.

22. Roudnicky F, Zhang JD, Kim BK, Pandya NJ, Lan YJ, Sach-Peltason L, Ragelle H, Strassburger P, Gruener S, Lazendic M, Uhles S, Revelant F, Eidam O, Sturm G, Kueppers V, Christensen K, Goldstein LD, Tzouros M, Banfai B, Modrusan Z, Graf M, Patsch C, Burcin M, Meyer CA, Westenskow $\mathrm{PD}$, Cowan CA. Inducers of the endothelial cell barrier identified through chemogenomic screening in genome-edited hPSC-endothelial cells. P Natl Acad Sci USA. 2020;117(37):23193-23193.

23. Wang $K$, Lin RZ, Hong XC, Ng AH, Lee CN, Neumeyer J, Wang G, Wang $X$, Ma ML, Pu WT, Church GM, Melero-Martin JM. Robust differentiation of human pluripotent stem cells into endothelial cells via temporal modulation of ETV2 with modified mRNA. Sci Adv. 2020. https://doi.org/10.1126/ sciadv.aba7606.

24. Roudnicky F, Kim BK, Lan YJ, Schmucki R, Kuppers V, Christensen K, Graf M, Patsch C, Burcin M, Meyer CA, Westenskow PD, Cowan CA. Identification of a combination of transcription factors that synergistically increases endothelial cell barrier resistance. Sci Rep. 2020. https://doi.org/10.1038/ s41598-020-60688-x.

25. Yamashita M, Aoki H, Hashita T, Iwao T, Matsunaga T. Inhibition of transforming growth factor beta signaling pathway promotes differentiation of human induced pluripotent stem cell-derived brain microvascular endothelial-like cells. Fluids Barriers Cns. 2020;17(1):36.

26. Gastfriend BD, Nishihara H, Canfield SG, Foreman KL, Engelhardt B, Palecek SP, Shusta EV. Wnt signaling mediates acquisition of blood-brain barrier properties in naive endothelium derived from human pluripotent stem cells. eLife. 2021. https://doi.org/10.7554/eLife.70992.

27. Linville RM, Sklar MB, Grifno GN, Nerenberg RF, Zhou J, Ye R, DeStefano JG, Guo Z, Jha R, Jamieson JJ, Zhao N, Searson PC. Three-dimensional microenvironment regulates gene expression, function, and tight junction dynamics of iPSC-derived blood-brain barrier microvessels. bioRxiv. 2021. https://doi.org/10.1101/2021.08.27.457975.

28. Thomsen MS, Routhe LJ, Moos T. The vascular basement membrane in the healthy and pathological brain. J Cereb Blood Flow Metab. 2017;37(10):3300-17.

29. Cucullo L, Hossain M, Puvenna V, Marchi N, Janigro D. The role of shear stress in blood-brain barrier endothelial physiology. BMC Neurosci. 2011;12:40.

30. Vatine GD, Barrile R, Workman MJ, Sances S, Barriga BK, Rahnama M, Barthakur S, Kasendra M, Lucchesi C, Kerns J, Wen N, Spivia WR, Chen Z, Van Eyk J, Svendsen CN. Human iPSC-derived blood-brain barrier chips enable disease modeling and personalized medicine applications. Cell Stem Cell. 2019;24(6):995-1005 e6.

31. Campisi M, Shin Y, Osaki T, Hajal C, Chiono V, Kamm RD. 3D self-organized microvascular model of the human blood-brain barrier with endothelial cells, pericytes and astrocytes. Biomaterials. 2018;180:117-29.

32. Jamieson JJ, Linville RM, Ding YY, Gerecht S, Searson PC. Role of iPSCderived pericytes on barrier function of iPSC-derived brain microvascular endothelial cells in 2D and 3D. Fluids Barriers CNS. 2019:16(1):15.

33. Ye M, Sanchez HM, Hultz M, Yang Z, Bogorad M, Wong AD, Searson PC. Brain microvascular endothelial cells resist elongation due to curvature and shear stress. Sci Rep. 2014;4:4681.

34. Curtaz CJ, Schmitt C, Herbert SL, Feldheim J, Schlegel N, Gosselet F, Hagemann C, Roewer N, Meybohm P, Wockel A, Burek M. Serum-derived factors of breast cancer patients with brain metastases alter permeability of a human blood-brain barrier model. Fluids Barriers CNS. 2020;17(1):31.

35. Chen MB, Yang AC, Yousef H, Lee D, Chen W, Schaum N, Lehallier B, Quake SR, Wyss-Coray T. Brain endothelial cells are exquisite sensors of agerelated circulatory cues. Cell Rep. 2020;30(13):4418.
36. Pulido RS, Munji RN, Chan TC, Quirk CR, Weiner GA, Weger BD, Rossi MJ, Elmsaouri S, Malfavon M, Deng A, Profaci CP, Blanchette M, Qian T, Foreman KL, Shusta EV, Gorman MR, Gachon F, Leutgeb S, Daneman R. Neuronal activity regulates blood-brain barrier efflux transport through endothelial circadian genes. Neuron. 2020;108(5):937-952 e7.

37. Bogorad MI, DeStefano J, Karlsson J, Wong AD, Gerecht S, Searson PC. Review: in vitro microvessel models. Lab Chip. 2015;15(22):4242-55.

38. Park TE, Mustafaoglu N, Herland A, Hasselkus R, Mannix R, FitzGerald EA, Prantil-Baun R, Watters A, Henry O, Benz M, Sanchez H, McCrea HJ, Goumnerova LC, Song HW, Palecek SP, Shusta E, Ingber DE. Hypoxia-enhanced blood-brain barrier chip recapitulates human barrier function and shuttling of drugs and antibodies. Nat Commun. 2019;10(1):2621.

39. Lyu Z, Park J, Kim KM, Jin HJ, Wu H, Rajadas J, Kim DH, Steinberg GK, Lee W. A neurovascular-unit-on-a-chip for the evaluation of the restorative potential of stem cell therapies for ischaemic stroke. Nat Biomed Eng. 2021;5(8):847-63.

40. Kim J, Lee KT, Lee JS, Shin J, Cui B, Yang K, Choi YS, Choi N, Lee SH, Lee JH, Bahn YS, Cho SW. Fungal brain infection modelled in a human-neurovascular-unit-on-a-chip with a functional blood-brain barrier. Nat Biomed Eng. 2021;5(8):830-46.

41. Linville RM, DeStefano JG, Sklar MB, Xu Z, Farrell AM, Bogorad MI, Chu C, Walczak P, Cheng L, Mahairaki V, Whartenby KA, Calabresi PA, Searson PC. Human iPSC-derived blood-brain barrier microvessels: validation of barrier function and endothelial cell behavior. Biomaterials. 2019:190-191:24-37.

42. Herland A, van der Meer AD, FitzGerald EA, ParkTE, Sleeboom JJ, Ingber DE. Distinct contributions of astrocytes and pericytes to neuroinflammation identified in a 3D human blood-brain barrier on a chip. PLoS ONE. 2016;11(3):e0150360.

\section{Publisher's Note}

Springer Nature remains neutral with regard to jurisdictional claims in published maps and institutional affiliations.

Ready to submit your research? Choose BMC and benefit from:

- fast, convenient online submission

- thorough peer review by experienced researchers in your field

- rapid publication on acceptance

- support for research data, including large and complex data types

- gold Open Access which fosters wider collaboration and increased citations

- maximum visibility for your research: over $100 \mathrm{M}$ website views per year

At BMC, research is always in progress.

Learn more biomedcentral.com/submissions 